\title{
An Investigation into Cold-Therapy of the Equine Metacarpus, Following Temperature Changes with Exercise as Well as Post Intervention
}

\author{
Simone Bøgelund Nielsen, Conny Breining Madvig, Adrian Paul Harrison* \\ Faculty of Health and Medical Sciences, PAS (Physiology), University of Copenhagen, Frederiksberg C, Copenhagen, Denmark \\ Email: ^adh@sund.ku.dk
}

How to cite this paper: Nielsen, S.B., Madvig, C.B. and Harrison, A.P. (2020) An Investigation into Cold-Therapy of the Equine Metacarpus, Following Temperature Changes with Exercise as Well as Post Intervention. Open Journal of Veterinary Medicine, 10, 185-194.

https://doi.org/10.4236/ojvm.2020.1010016

Received: September 8, 2020

Accepted: October 20, 2020

Published: October 23, 2020

Copyright $\odot 2020$ by author(s) and Scientific Research Publishing Inc. This work is licensed under the Creative Commons Attribution International License (CC BY 4.0).

http://creativecommons.org/licenses/by/4.0/

(c) (i) Open Access

\begin{abstract}
There is some discussion as to whether exercise-induced hyperthermia of the superficial digital flexor tendon (SDFT) affects tenocyte viability and pre-disposes to injury. Cold-therapy is commonly used as a preventative measure and treatment for acute tendon injuries, but only a few studies have evaluated the effect of cold-therapy on metacarpal temperatures in the horse. For this reason, this study has measured skin surface temperatures after moderate exercise and after application of cold-therapy, and additionally monitored the duration of any effects. Four horses were recruited into a semi blinded controlled study with repeated measurements that involved lunged exercise for 16 minutes at moderate intensity. Skin surface temperature was measured using a thermographic camera before and after lunging, and every 40 minutes for two hours post cold-therapy. Cold-therapy was applied using a Jacks Whirlpool Boot with ice-water immersion at a level just distal to the carpus for 20 minutes. The right leg was treated, and the left leg was used as an untreated control. The experiment was conducted twice on all four horses. Moderate exercise resulted in an increase in skin surface temperature of $10^{\circ} \mathrm{C}$. Application of cold-therapy for 20 minutes resulted in a reduction in skin surface temperature by $14^{\circ} \mathrm{C}$. The effect of cold-therapy persisted for at least 40 minutes post treatment. It is concluded that exercise leads to an increase in skin surface temperature which is counteracted by the application of cold-therapy. These findings would seem to indicate that cold-therapy can be used after exercise to counteract hyperthermia within the metacarpal region of the horse's leg.
\end{abstract}

\section{Keywords}

Horse, Thermography, Hyperthermia, Water Immersion, Cooling, 


\section{Introduction}

There are many theories behind the pathophysiology of tendon injuries. One is that the increase in temperature during locomotion leads to degenerative changes to the tendon fibers. The temperature within the equine metacarpus is known to rise during exercise [1] [2]. Indeed, studies have shown that the temperature within the equine metacarpus rises during exercise as a result of hysteresis when the energy stored in the flexor tendons during the weight-bearing phase is released during locomotion. Temperatures within the superficial flexor tendon (SDFT) have been shown to reach $45^{\circ} \mathrm{C}$ after 10 minutes of galloping [2] or $43^{\circ} \mathrm{C}$ after 3 - 4 minutes of flat racing [3]. It is this increase in temperature that is believed to cause accumulative micro-damage to the tendon fibers, hence pre-disposing them to rupture [4].

In vitro studies evaluating the viability of tenocytes after absorbing heat have shown that tenocyte cell death can be induced when they are heated to $46^{\circ} \mathrm{C}$ $48^{\circ} \mathrm{C}$ for 10 minutes [5]. Furthermore, tenocytes heated to $45^{\circ} \mathrm{C}$ for 1 hour had an almost $100 \%$ mortality rate [3]. Besides this, tenocytes are known to synthesize pro-inflammatory cytokines such as tumor necrosis factor alpha (TNF-alpha) and promatrix metalloproteinases (proMMP-9) [6], thereby potentially inducing an inflammatory response as a result of an increase in temperature. Studies have shown that stressed tenocytes show an altered protein synthesis resulting in the production of collagen type III rather than type I [4], leading to a tendon with a reduced stretch resistance.

The use of cold-therapy in the equine metacarpus has therefore the potential to fulfill two purposes, 1) to act as a preventative measure, and 2) to serve as a management tool for acute tendon injury. The theory when using cold-therapy as a preventative measure is to shorten the period of time in which the tendon experiences an increase in temperature, potentially inducing tenocyte death, as well as the production of pro-inflammatory mediators and an altered protein synthesis. During the acute phase of an injury, cold-therapy is believed to inhibit the pro-inflammatory response through a cold-mediated sympathetic effect and through its inhibition of TNF-alpha production [6]. In addition, cold-therapy is known to cause pain relief in humans [7], although the precise mechanism behind this analgesic effect has yet to be elucidated.

Though many cold-therapy products are freely available on the market, only a few studies have been conducted to verify the actual effect of their use and efficacy. This study was therefore undertaken with the aim of; 1) measuring the skin surface temperature of the equine metacarpus after 16 minutes of lunging exercise, and 2) assessing the beneficial effect of 20 minutes of cold-therapy, using a Jacks Whirlpool Boot with circulating ice-water, in terms of lowering any exer- 
cise-induced rise in skin surface temperature as well as the duration of any changes. The hypotheses tested by this study were that; 1 ) exercise leads to an increase in skin surface temperature in the distal equine limb, and 2) cold-therapy using a Jacks Whirlpool Boot leads to a temperature decrease in the treated limb when compared to the untreated control.

\section{Materials and Methods}

The experiment outline for the present study was to measure whether an increase in skin surface temperature associated with exercise in the equine distal limb occurred, and thereafter to assess the efficacy of a means of cooling the said distal limbs.

Animals. This study was performed as a semi blinded controlled study with repeated measurements over a period of four days. In terms of the semi blinded aspect of this study, SBN always measured the equine distal limb temperatures, reporting the values to CBM, and at no time during the study was SBN permitted to see the temperature recordings, thus remaining semi blinded to the effects of exercise and cooling. In total four healthy horses were measured twice after gaining full consent from the owners. All four horses were observed by qualified personnel (SBN \& CBM) to move naturally with no signs of lameness for three basic gaits: a four-beat walk, a two-beat trot and a three-beat canter, before and after the experiment. All four of the horses in this study were Danish warmbloods; age range 3 - 13 years (mean 8.75 years).

Exercise: The horses were lunged on a soft surface for 4 minutes at the trot on both reins, starting by lunging to the left, followed by 4 minutes of canter on both reins, again starting by lunging to the left. No leg-protectors were used.

Measurements. Skin surface temperatures were measured before lunging, immediately after lunging, immediately after 20 minutes of cold-therapy and then again 40, 80 and 120 minutes post cold-therapy. Four measurement points were evaluated at each of the aforementioned times (see Figure 1), these being the insertion of the suspensory ligament (SL) (lateral aspect), both the proximal and the palmar superficial digital flexor tendon (SDFT), and the lateral branch of the SL. It should be noted that one of the horses (no. 3) was sedated during all of the measurements with $0.5 \mathrm{ml}$ Detomidine (Cepsedan vet $10 \mathrm{mg} / \mathrm{ml}$; Modern Veterinary Therapeutics LLC, Miami, FL 33157, USA), $0.5 \mathrm{ml}$ Butorphanol (Morphasol vet $10 \mathrm{mg} / \mathrm{ml}$; aniMedica GmbH, 48308 Sedan-Bösensell, D) and 1 $\mathrm{ml}$ Acepromazine (Plegicil vet $10 \mathrm{mg} / \mathrm{ml}$; Pharmaxim AB, 25368 Helsingborg, S). Furthermore, another horse (no. 4) was sedated with the same combination as horse no. 3, but only on the first day of measurement. The outdoor temperature varied from $10^{\circ} \mathrm{C}-12^{\circ} \mathrm{C}$ on the measurement days (mean $=10.5^{\circ} \mathrm{C}$ ). All horses tolerated the cold-therapy well and no side-effects where observed in either of the horses immediately post cold-therapy, nor 24-hours after the treatment.

A Professional Thermal imaging camera (Bosch GmbH, GTC 400 C, Gerlingen, D) was used, with the emissivity degree set at 0.98 , as this is the emissivity 
of human skin [8]. The surface temperature measurement range was $-10^{\circ} \mathrm{C}$ to $+400^{\circ} \mathrm{C}$ with accuracy at $\pm 3^{\circ} \mathrm{C}$.

Intervention: Cold-therapy was applied using a Jacks Whirlpool Boot (Washington C.H., OH 43160, USA). During the experiment, the right limb of each horse was cooled, while the left limb acted as a non-treated control.

The Jacks Whirlpool Boot was filled with a mixture of water and cubes of ice to give a temperature of approximately $6^{\circ} \mathrm{C}$, and it was filled to a level just below the carpus. Treatment was for 20 minutes, which is the current recommended duration of cold-therapy for horses [9]. The temperature of the water was maintained at $6^{\circ} \mathrm{C}$, something that this is achievable at competitions or in the stable without having to use supplementary equipment other than water and ice-cubes. According to the Fédération Equestre Internationale (FEI) regulations, cold-therapy is allowed at competitions if the level of cooling is kept above $0^{\circ} \mathrm{C}$ [10]. The temperature of the water in this study ensured that the FEI regulations were respected.

Study limitations. Perhaps the greatest limitation in the present study was the number of horses included, although this study was run in a semi blinded fashion and with repeated measures by way of compensation. Another limitation or perhaps disadvantage associated with the present study was the need for sedation in one of the horses, which was deemed necessary when using the Jacks Whirlpool Boot with a young horse. This therapy requires that the horse is not only familiar with the boot, but is also able to stand still for 20 minutes during the therapy.

\section{Statistical analysis:}

The data were first evaluated using a Kolmogorov-Smirnov test to evaluate if there was normally distributed and then a 2-way ANOVA was used to compare the two independent variables: limb and cold-therapy. Statistical tests were performed using Prism 8 (mac 8.4.1; GraphPad Software LLC, San Diego, CA 92108, USA). Data are presented as the mean \pm SD, and statistical significance was noted when the $p$-value was less than 0.05 .

\section{Results}

The horses measured in this study were analyzed in terms of the four measurement sites, the palmar superficial digital flexor tendon, the proximal superficial digital flexor tendon, the proximal insertion of the suspensory ligament, and the lateral branch of the suspensory ligament (see Figure 2).

Palmar SDFT: The temperature was measured before lunging and immediately after lunging. The temperature increased from $20.6^{\circ} \mathrm{C} \pm 2.4^{\circ} \mathrm{C}$ (left limb) and $20.3^{\circ} \mathrm{C} \pm 3.1^{\circ} \mathrm{C}$ (right limb) to $31.8^{\circ} \mathrm{C} \pm 2.6^{\circ} \mathrm{C}$ (left limb) and $30.8^{\circ} \mathrm{C} \pm 2.7^{\circ} \mathrm{C}$ (right limb) after 16 minutes of lunging. It was found that 20 minutes of cold-therapy led to a decrease in temperature with the mean of the left and right limb being $29.2^{\circ} \mathrm{C} \pm 3.4^{\circ} \mathrm{C}$ and $15.1^{\circ} \mathrm{C} \pm 8.7^{\circ} \mathrm{C}$ respectively, which was significantly different $(P<0.0001)$. The surface temperature slowly increased over the 120 minutes following cold-therapy, with a temperature difference of significance 


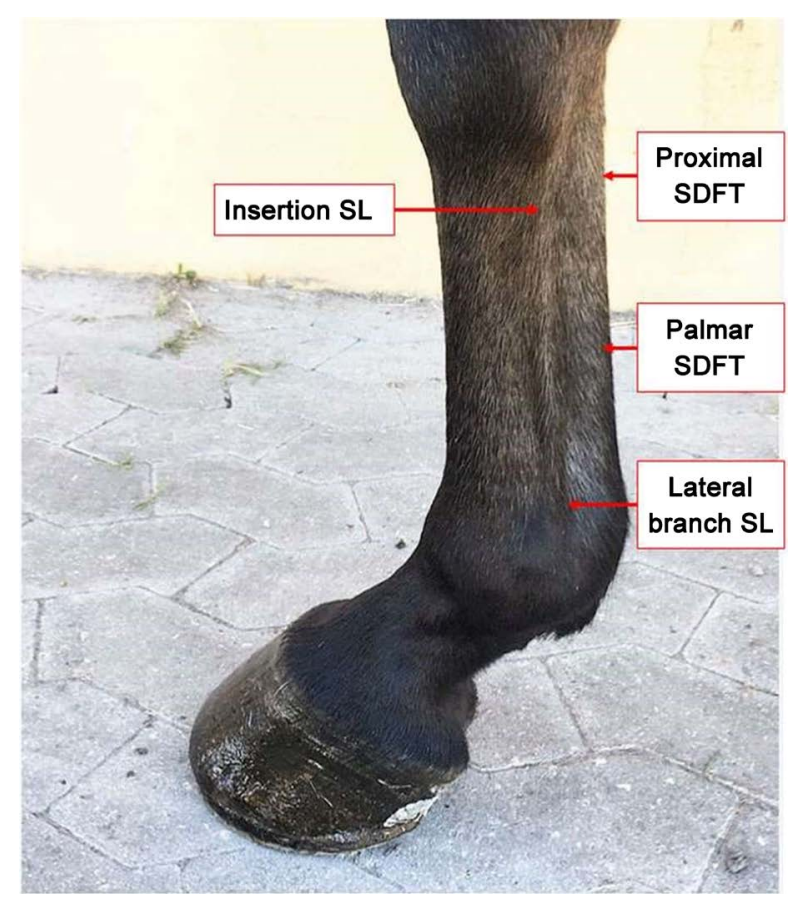

Figure 1. Photograph of the measuring points used in this study. Palmar superficial digital flexor tendon (Palmar SDFT), the proximal superficial digital flexor tendon (Proximal SDFT), the proximal insertion of the suspensory ligament (Insertion SL), and the lateral branch of the suspensory ligament (Lateral branch SL).

for the first 80 minutes following treatment. The right limb did not reach the same temperatures as the left limb during the total duration of the study in any horses (120 minutes post cold-therapy).

Proximal SDFT: The temperature was measured before lunging and immediately after lunging. The temperature increased from $23.0^{\circ} \mathrm{C} \pm 2.7^{\circ} \mathrm{C}$ (left limb) and $21.6^{\circ} \mathrm{C} \pm 2.3^{\circ} \mathrm{C}$ (right limb) to $32.1^{\circ} \mathrm{C} \pm 2.5^{\circ} \mathrm{C}$ (left limb) and $31.7^{\circ} \mathrm{C} \pm 2.3^{\circ} \mathrm{C}$ (right limb) after 16 minutes of lunging. It was found that 20 minutes of cold-therapy led to a decrease in temperature with the mean of the left and right limb being $29.0^{\circ} \mathrm{C} \pm 3.2^{\circ} \mathrm{C}$ and $15.1^{\circ} \mathrm{C} \pm 7.8^{\circ} \mathrm{C}$, respectively, showing a temperature difference that was statistically significant $(P<0.0001)$. The surface temperature slowly increased over the 120 minutes following cold-therapy, with a temperature difference of significance for the first 40 minutes following treatment. The right limb did not reach the same temperatures as the left limb during the total duration of the study (120 minutes post cold-therapy).

Proximal insertion of the $S L$ : The temperature was measured before lunging and immediately after lunging. The temperature increased from $22.2^{\circ} \mathrm{C} \pm 2.4^{\circ} \mathrm{C}$ (left limb) and $22.1^{\circ} \mathrm{C} \pm 2.5^{\circ} \mathrm{C}$ (right limb) to $32.1^{\circ} \mathrm{C} \pm 2.3^{\circ} \mathrm{C}$ (left limb) and $31.3^{\circ} \mathrm{C} \pm 3.2^{\circ} \mathrm{C}$ (right limb) after 16 minutes of lunging. It was found that 20 minutes of cold-therapy led to a decrease in temperature with the mean of the left and right limb being $29.7^{\circ} \mathrm{C} \pm 2.6^{\circ} \mathrm{C}$ and $16.8^{\circ} \mathrm{C} \pm 7.9^{\circ} \mathrm{C}$, respectively, showing a temperature difference that was statistically significant $(P<0.0001)$. The surface temperature slowly increased over the 120 minutes following cold-therapy, with a 

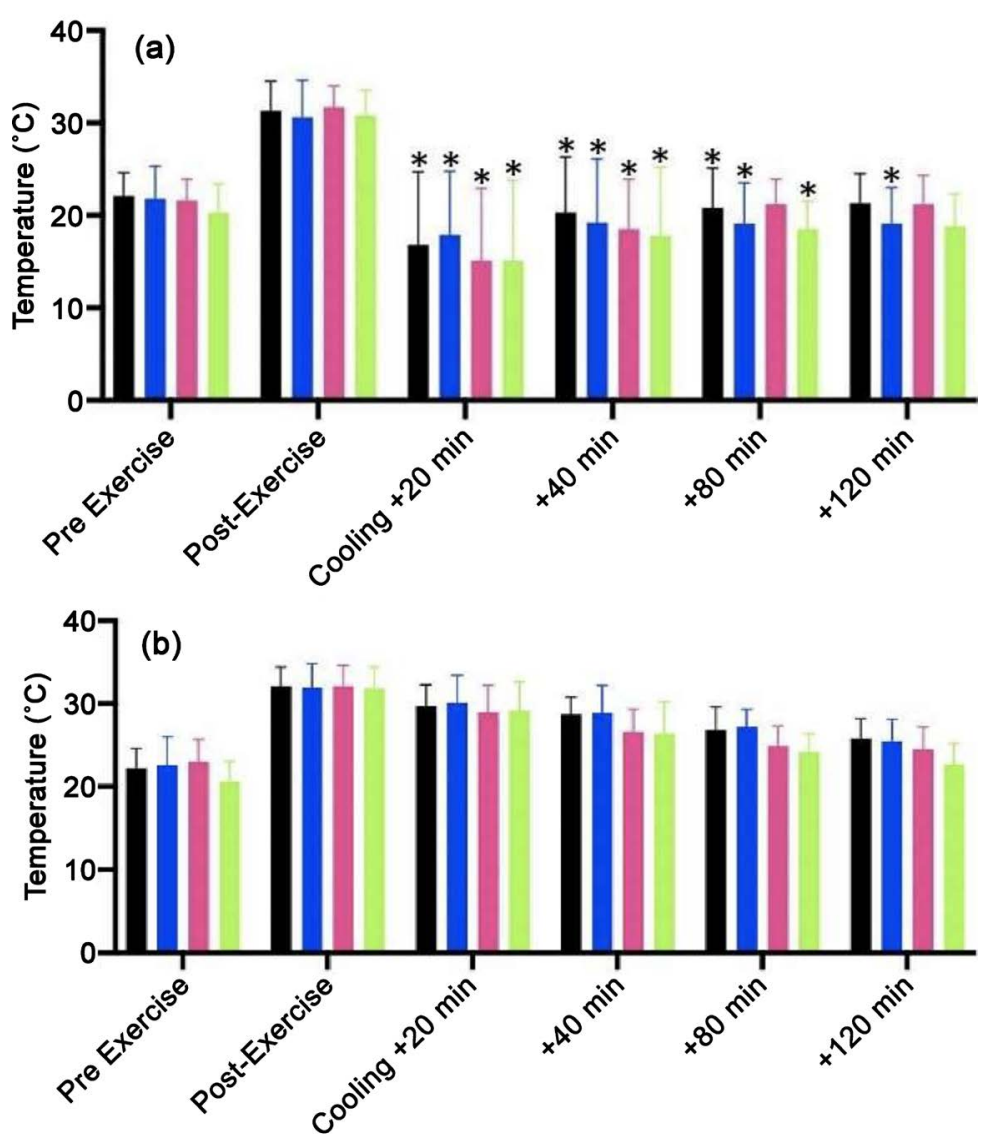

Figure 2. 2a (right limb) and 2b (left limb):The effect of cold-therapy on the skin surface temperature on the treated right limb, and the left non-treated control limb. Mean temperatures \pm SD recorded pre-exercise, post-exercise, immediately post 20 minutes of cold-therapy, 40, 80 and 120 minutes post cold-therapy. The temperatures were measured for both legs at the insertion of the suspensory ligament (SL; black column), the lateral branch of the SL (blue column), the proximal superficial digital flexor tendon (SDFT; pink column) and the palmar aspect of the SDFT (green column). $A *$ denotes statistical significance at the level of $P<0.05$ when compared to the non-treated left limb.

temperature of significance for all of the 120 minutes following treatment, that is to say that the right limb never reached the temperature of the left limb within two hours of cold-therapy.

Lateral branch of the SL: The temperature was measured before lunging and immediately after lunging. The temperature increased from $22.6^{\circ} \mathrm{C} \pm 3.4^{\circ} \mathrm{C}$ (left limb) and $21.8^{\circ} \mathrm{C} \pm 3.5^{\circ} \mathrm{C}$ (right limb) to $31.9^{\circ} \mathrm{C} \pm 2.9^{\circ} \mathrm{C}$ (left limb) and $30.6^{\circ} \mathrm{C} \pm$ $4.0^{\circ} \mathrm{C}$ (right limb) after 16 minutes of lunging. It was found that 20 minutes of cold-therapy lead to a decrease in temperature with the mean of the left and right limb being $28.9^{\circ} \mathrm{C} \pm 3.3^{\circ} \mathrm{C}$ and $19.2^{\circ} \mathrm{C} \pm 6.9^{\circ} \mathrm{C}$, respectively, showing a temperature difference that was statistically significant $(P<0.0001)$. The surface temperature slowly increased over the 120 minutes following cold-therapy, with a temperature of significance for all of the 120 minutes following the cold-therapy, that is to say that the right limb never reached the temperature of the left limb within two hours of cold-therapy. 


\section{Discussion}

This study has shown that exercise, even of a moderate intensity, leads to a rise in skin surface temperature in the equine metacarpal region, thereby confirming the hypothesis. The palmar surface temperature of the limbs was found to increase, by approximately $10^{\circ} \mathrm{C}$ when lunging the horses for a period of just 16 minutes. A similar and recent study conducted by Quintanar and colleagues (2018) found that lunging for 19 minutes led to a decrease in the skin surface temperature for the dorsal aspect of the metacarpus; a decrease that ranged from $2.0^{\circ} \mathrm{C}$ to $6.9^{\circ} \mathrm{C}[11]$. Of course, these authors measured from the dorsal aspect of the metacarpal region, whilst the present study has focused on the palmar surface, which may explain the finding of an increase in temperature after just 16 minutes of lunging. These findings could be interpreted as indicating hysteresis [1], such that the majority of the temperature increase at the palmar surface in fact mimics an increase in temperature within the flexor tendons. Likewise, the decrease in skin temperature observed by Quintanar and colleagues (2018) at the dorsal surface may be related to a cooling effect of ambient air as a result of limb movement with exercise [11].

This study has also shown that cold-therapy, using on this occasion a Jacks Whirlpool Boot, leads to a temperature decrease between the treated limb and the untreated control. Indeed, just 20 minutes of cold-therapy using ice-water immersion (approximately $6^{\circ} \mathrm{C}$ ) and a Jacks Whirlpool Boot with circulation, resulted in a significant decrease in the skin surface temperature compared with control legs. Similar results were found by Kaneps (2000) who reported that cold water immersion for 40 minutes on average led to a skin surface temperature decrease of $18.5^{\circ} \mathrm{C}[12]$.

The present study has also revealed that the difference between the cold-treated limb and the non-treated control limb persists for 120 minutes for all four parameters with the temperature difference being of significance for the first 80 minutes post cold-therapy on the palmar skin surface of the SDFT and the SL insertion, for 40 minutes on the proximal SDFT and 120 minutes at the lateral branches of the SL. This is a most interesting finding, as it suggests that cold-therapy leads to a reduction of skin surface temperature that lasts for at least 30 minutes post treatment.

It is likewise interesting to note that an individual difference in response to cold-therapy was observed with the present study. Horse number 4 in the present study showed a higher starting temperature for both limbs than any of the other horses. This was the case on both measuring days. On the first day of measurement, this horse barely showed any decrease in skin surface temperature after 20 minutes of cold-therapy. The precise reason for this difference remains unknown, although we speculate that the age of the horse (three years old) and/or the sedation used on the first day $(0.5 \mathrm{ml}$ Detomidine (Cepsedan vet 10 $\mathrm{mg} / \mathrm{ml}$ ), $0.5 \mathrm{ml}$ Butorphanol (Morphasol vet $10 \mathrm{mg} / \mathrm{ml}$ ) and $1 \mathrm{ml}$ Acepromazine (Plegicil vet $10 \mathrm{mg} / \mathrm{ml})$ ) might explain in part this observation. This particular 
horse showed a decrease in temperature of roughly $10^{\circ} \mathrm{C}$ on the second day of measurement when no sedation was used. The assumption being therefore that the sedative used on the first day of measurement somehow affected the circulation of the thoracic limb. In support of which, detomidine, which is an $\alpha_{2}$-agonist, is known to cause a decrease in heart rate and induce a bi-phasic vascular response initially causing hypertension followed by hypotension [13]. Acepromazine can likewise induce vasodilation, hypotension and a decrease in cardiac output [14], whilst butorphanol is not known to have any significant effect on the cardiovascular system [15]. However, we know of no studies that have evaluated this exact combination of detomidine, acepromazine and butorphanol and their effect on the cardiovascular system.

On a positive note, none of the horses in this study showed any signs of discomfort, skin irritation, edema, or other adverse effects during, or after (24 hours) cold-therapy treatment. That having been said, that whilst cold-therapy using ice-water immersion for 20 minutes appears to be a safe form of treatment in the equine limb, the effect of this treatment on nerves should now be evaluated.

There is a disadvantage of this study, however, and that is that the authors have found that horses need to be familiar with the system used (Jacks Whirlpool Boot), they also need to be able to stand still for 20 minutes during the therapy. This system also requires electricity in order to keep the water circulating, something that might not be readily available in the field. To this end, a number of other systems are available which consist of various kinds of bandages or wraps, being more user-friendly at competitions in the field or in stables where mains electricity is not readily available, although it should be said that ice-water immersion is superior to many of these alternative systems [12] [16].

Finally, since this study has only evaluated skin surface temperature, more research on the correlation between skin surface temperature and the core temperature of the SDFT and SL is now highly relevant. Wilson and Goodship (1994) developed a mathematical formula for predicting the core temperature of the SDFT when the surface temperature of the SDFT was known [1]. This model predicts that the core should be $11^{\circ} \mathrm{C}$ warmer than the tendon surface, however, when tested, the core of the tendon proved to only show a $5^{\circ} \mathrm{C}$ higher temperature than the tendon surface [1].

\section{Conclusion}

This study has shown that moderate exercise leads to a measurable increase in the skin surface temperature of the metacarpus, and furthermore, that the use of ice-water immersion effectively decreases the skin surface temperature in this area. A significant decrease in skin surface temperature was found to last for at least 40 minutes post treatment. Whilst it was beyond the scope of this study to directly compare different methods of limb cooling, this should now be the focus of any future investigations. Likewise, the development of a model for skin sur- 
face and tendon core temperature correlations would prove valuable as an evidence-based therapeutic index specialized for the equine metacarpal region.

\section{Acknowledgements}

The authors would like to thank not only the horse owners for their very kind help with this study but also the stable owners for granting permission for this study to be performed on their premises and with their facilities. The authors would also like to express a special thanks to Tom Bruno Pedersen for kindly providing the Professional Thermal imaging camera. Finally, it should be noted that SBN has a degree as a qualified horse trainer.

\section{Conflicts of Interest}

The authors declare no conflicts of interest regarding the publication of this paper.

\section{References}

[1] Smith, R.K.W. (2010) Pathophysiology of Tendon Injury. In: Ross, M.W. and Dyson, S.J., Eds., Diagnosis and Management of Lameness in the Horse, 2nd Edition, Elsevier Saunders, Missouri, 694-706. https://doi.org/10.1016/B978-1-4160-6069-7.00068-7

[2] Wilson, A.M. and Goodship, A.E. (1994) Exercise-Induced Hyperthermia as a Possible Mechanism for Tendon Degeneration, Journal of Applied Biomechanics, 27, 899-901, 903-905. https://doi.org/10.1016/0021-9290(94)90262-3

[3] Yamasaki, H., Goto, M., Yoshihara, T., Sekiguchi, M., Konno, K., Momoi, Y., and Iwasaki, T. (2001) Exercise-Induced Superficial Digital Flexor Tendon Hyperthermia and the Effect of Cooling Sheets on Thoroughbreds. Journal of Equine Science, 12, 85-91.

[4] Birch, H.L., Bailey, A.J. and Goodship, A.E. (1998) Macroscopic Degeneration of Equine Superficial Digital Flexor Tendon Is Accompanied by a Change in Extra Cellularmatrix Composition. Equine Veterinary Journal, 30, 534-539. https://doi.org/10.1111/j.2042-3306.1998.tb04530.x

[5] Birch, H.L., Wilson, A.M. and Goodship, A.E. (1997) The Effect of Exercise-Induced Localized Hyperthermia on the Tendon Cell Survival. Journal of Experimental Biology, 200, 1703-1708.

[6] Hosaka, Y., Ozoe, S., Kirisawa, R., Ueda, H., Takehana, K. and Yamaguchi, M. (2006) Effect of Heat on Synthesis of Gelatinases and Pro-Inflammatory Cytokines in Equine Tendinocytes. Biomedical Research, 27, 233-241.

[7] Ingram, J., Dawson, B., Goodman, C., Wallman, K. and Beilby, J. (2009) Effect of Water Immersion Methods on Post-Exercise Recovery from Simulated Team Sport Exercise. Journal of Science and Medicine in Sport, 12, 417-421.

https://doi.org/10.1016/j.jsams.2007.12.011

[8] Keenan, E., Gethin, G., Flynn, L., Watterson, D. and O’Connor, G.M. (2017) Enhanced Thermal Imaging of Wound Tissue for Better Clinical Decision Making. Physiological Measurement, 38, 1104. https://doi.org/10.1088/1361-6579/aa6ea0

[9] Avella, C.S. and Smith, R.K.W. (2018) Diagnosis and Management of Tendon and Ligament Disorders. In: Auer, J.A. and Stick, J.A., Eds., Equine Surgery, 5th Edition, Saunders Co., Philadelphia, 1425. 
[10] Fédération Équestre Internationale (2020) FEI Veterinary Rules. 2020 Veterinary Regulations, 14th Edition 2018, Effective 1st January 2020.

https://inside.fei.org/sites/default/files/FEI\%20Rules/FEI\%20Veterinary\%20Regulati ons\%202020\%20-\%20Clean\%20Version.pdf

[11] Quintanar, M.N., Millar, T.P. and Burd, M.A. (2018) Thermodynamic Effects of Commercially Available Ice Boots. Open Veterinary Journal, 8, 5-8.

https://doi.org/10.4314/ovj.v8i1.2

[12] Kaneps, A.J. (2000) Tissue Temperature Response to Hot and Cold Therapy in the Metacarpal Region of a Horse. AAEP, 46, 208-213.

[13] Yamashita, K., Tsubakishita, S., Futaoka, S., Ueda, I., Hamaguchi, H., Seno, T., Katoh, S., Izumisawa, Y., Kotani, T. and Muir, W.W. (2000) Cardiovascular Effects of Medetomidine, Detomidine and Xylazine in Horses. Journal of Veterinary Medical Science, 62, 1025-1032. https://doi.org/10.1292/jvms.62.1025

[14] Posner, L.P. (2018) Sedatives and Tranquilizers. In: Riviere, J.E. and Papich, M.G., Eds., Veterinary Pharmacology and Terapeutics, 5th Edition, John Wiley \& Sons, Inc, Hoboken, 325.

[15] KuKanich, B. and Papich, M.G. (2018) Opioid Analgesic Drugs. In: Riviere, J.E. and Papich, M.G., Eds., Veterinary Pharmacology and Terapeutics, 5th Edition, John Wiley \& Sons, Inc, Hoboken, 307.

[16] van Eps, A.W. and Orsini, J.A. (2016) A Comparison of Seven Methods for Continuous Therapeutic Cooling of the Equine Digit. Equine Veterinary Journal, 48, 120-124. https://doi.org/10.1111/evj.12384 